\title{
Construção e re-construção da identidade nas histórias de vida de adotados
}

\author{
Margarida Rangel Henriques \\ André Guirland Vieira \\ Dóris Cristina Gedrat
}

Resumo: O objetivo deste estudo é identificar como a adoção aparece nas histórias de vida de indivíduos adotados e como eles normalizam suas experiências relacionadas à adoção. Focaliza-se a re-historiação do "eu" na narrativa e considera-se que o seu final é determinado por quem constrói a narrativa, não por eventos relatados cronologicamente. Os dados provêm das narrativas de dois indivíduos adotados, transcritas segundo convenções utilizadas na Análise da Conversa Etnometodológica, nas quais se destaca a presença dos eventos relacionados à adoção na re-historiação dos pesquisados e na constituição de seus "eus" parciais, considerando também as características rítmicas e outras propriedades da fala em interação. Foi possível constatar que o final da história influencia na maneira como a narrativa é construída e como as experiências de adoção aparecem nas narrativas, com maior ou menor grau de normalização a elas atribuído.

Palavras-chave: Narrativa; Identidade; Adoção.

\section{Identity construction and re-construction in life stories of adopted individuals}

\begin{abstract}
This study aims at identifying how adoption appears in life stories of adopted individuals and how much they normalize their experiences related to adoption. Focus is given to the process of re-historization of the "I", and the end of a narrative is taken as determined by its author instead of the events that are told chronologically. The data comes from narratives of two adopted individuals, transcribed according to Etnomethodological Conversation Analysis. It is pointed out how the events related to adoption appear, when both individuals re-historize their life stories and their partial "I" is constituted. Rhythmical properties and other characteristics of speech are considered in the investigation as well. It was found that the story ending influences on how the narrative is constructed and on how much normalized events related to adoption appear.
\end{abstract}

Keywords: Narrative; Identity; Adoption.

\section{Introdução}

O processo de construção da identidade consiste no desenvolvimento de um sentido de unidade e de propósito diante das demandas do mundo e da sociedade no qual os jovens reorganizam e reconstroem sua história de vida, a fim de produzir uma narrativa autobiográfica coerente (McAdams, 2001). A formação de uma identidade narrativa envolve a construção de histórias coerentes, com a finalidade de criar e comunicar um sentido de identidade e de significado (Reese, Yan, Jack \& Hayne, 2010). É durante a adolescência que surge a necessidade de construção de uma identidade que permita à pessoa uma relação produtiva com o mundo (Erikson, 1968; McAdams, 2001; Habermas \& Bluck, 2000).

Estudar a narrativa, tanto em seu aspecto canônico e estrutural como em suas variações ou desvios, significa estudar como as pessoas organizam o seu conhecimento na forma de representações de suas experiências atuais ou passadas com o mundo (Vieira \& Henriques, 2014). Por isso, a narrativa pode ser tomada como fundamento para a compreensão da ação humana, pois tanto o ser humano individual como a humanidade em geral organizam o conhecimento de sua experiência com o mundo em uma forma narrativa (Bruner, 1990; Correia, 2003).

Neste trabalho, o objetivo é identificar como a adoção aparece nas histórias de vida de indivíduos com essa experiência, considerando a re-historiação do "eu" na narrativa e a função do final da história na determinação da maneira como a narrativa é construída, como os eventos são organizados, adquirem significações e como os eventos anteriores na sequência funcionam como começos e meios na re-historiação que o narrador faz ao contar a sua história (Mishler, 2002; Riccoeur, 1980; Kermode, 1967; Doctorow, 2000), normalizando as experiências relacionadas à adoção com maior ou menor grau (Sacks, 1984).

O presente texto organiza-se iniciando com a diferenciação entre o modelo descritivo de tempo do relógio/cronológico versus o modelo descritivo de tempo narrativo/experiencial (Mishler, 2002) e a concepção de que ao contar sua história de vida, o narrador faz a re-historiação dos fatos de sua vida a partir do final da história narrada. Para que a narrativa seja construída, primeiro se deve determinar o seu término, para que, a partir dele, os eventos adquiram significações e seja feita a organização do que vem 
antes e depois na narrativa. Nesta etapa, apresenta-se, também, a teoria de Sacks (1984), quanto à normalização que os indivíduos tendem a fazer ao narrarem suas histórias de vida.

$\mathrm{Na}$ sequência, aborda-se a construção da identidade mediante a narrativização dos fatos (McAdams \& McLean, 2013; Fivush, 2008; Fivush \& Baker-Ward, 2005; Fivush \& Buckner, 1998; Fivush \& Haden, 2003) e as demandas socioculturais para um posicionamento dentro da sociedade (Habermas, 2007; Habermas \& Bluck, 2000), as quais culminam na necessidade e na possibilidade de construção de uma identidade socioculturalmente situada. Quanto à condição de adoção, mostra-se que a identidade narrativa de jovens adultos adotados é marcada pelo sentimento de uma ruptura com o passado. Essa ruptura provoca nessas pessoas o movimento de busca que Carsten chamou de 'knowing where you've come from' (Carsten, 2000; Yngvesson, 2007).

Finalmente, apresenta-se um estudo feito com dois casos de adoção já pesquisados por Vieira (2012), em cujas narrativas se identifica a re-historiação no que tange aos eventos relacionados à adoção e à função do final de uma narrativa na determinação de como ela será construída, que eventos participarão da história e como se organizam e reorganizam na sequência da história de vida. Além disso, observa-se como o fato de terem sido adotados é uma experiência narrada como normal pelos participantes entrevistados. Como o final de cada narrativa, que, na verdade, é seu ponto de partida, difere drasticamente em cada caso, no tocante à visão do narrador sobre sua adoção, pode-se constatar diferenças significativas no processo de re-historiação feito pelos narradores e, consequentemente, na constituição de seus “eus” parciais, conforme noção de Mishler (2002). Igualmente, a normalização das experiências de adoção aparece diferentemente nas narrativas dos dois indivíduos adotados.

\section{Narrativas de vida: temporalidade e experienciação dos fatos narrados}

No campo da psicologia discursiva, há um grande interesse pelas histórias de vida produzidas em situação de entrevista, analisadas, sobretudo, para a compreensão do desenvolvimento e da construção da subjetividade dos entrevistados (Freeman, 2006). Bastos e Biar (2015, p.4) mostram que "a narrativa é tradicionalmente definida como forma de se recapitularem discursivamente experiências passadas a partir de uma articulação sequencial de orações", entendendo-se a sequência como "uma propriedade linguístico-discursiva representativa de uma ordem cronológica dos eventos passados em um postulado mundo real" (segundo Labov \& Waletzky, 1967 e Labov, 1972 apud Bastos e Biar, 2015, p. 4).

As autoras (Bastos \& Biar, 2015), então, continuam traçando o histórico dos estudos da narrativa e apontam que autores contemporâneos revisaram o trabalho pioneiro e ampliaram suas definições formais, além de incluir sob o escopo de análise segmentos não-canônicos (Bamberg \& Georgakopoulou, 2008) e considerar a sua emergência em contextos interacionais diversos (Sacks 1984; Mishler, 1986, 2002). Outros ainda problematizam as concepções realistas/representacionistas sobre narrativa patentes nos trabalhos pioneiros. Alguns autores argumentam que as histórias de vida são construídas mais em função de certos cânones culturais que de sua alegada capacidade de representar eventos. Outros, diferentemente, exploram as funções da ordem temporal em narrativas, fazendo uma distinção entre tempo cronológico e tempo experiencial. Esses autores apresentam em comum a tomada da narrativa como uma forma de constituir uma realidade sempre revogável e a serviço de padrões culturais e interacionais (Bruner, 1990; Linde, 1993; Mishler, 1999, 2002), reivindicando para as narrativas funções mais complexas e mais comuns à experiência cotidiana, relacionadas à construção de sociabilidade, à conformação da experiência em padrões públicos de aceitação e à construção de um sentido de quem somos e do mundo que nos cerca, nossa identidade (Bastos \& Biar, 2015, p.101).

Linde (1993) destaca a questão das expectativas sociais em relação às histórias de vida que os indivíduos contam. Estas, segundo a autora, abordam as construções sociais mais amplas, uma vez que fazem pressuposições sobre o que pode ser esperado, o que são as normas e que sistemas comuns ou especiais de crenças podem ser usados para estabelecer coerência. "Não somos livres para construir uma história de vida de qualquer maneira. Os interlocutores fazem vários tipos de exigências sociais quanto à natureza da história a ser contada." (Linde, 1993, p. 7)

Para satisfazer as expectativas sobre o que e como construir uma narrativa de vida, existem convenções específicas que governam o que pode e o que não deve integrar uma história de vida. Tais convenções não são universais, assim como a própria noção de história de vida não é universal; pelo contrário, difere de acordo com a cultura e a subcultura. Essa posição tomada por Linde (1993) revela a diferença de uma visão de narrativa que segue o modelo descritivo de tempo do relógio/cronológico versus a visão que segue o modelo descritivo de tempo narrativo/experiencial, apontado em Mishler (2002). 
Mishler (2002) ressalta a função que o ato de narrativizar tem na reatribuição de significado aos eventos passados, ao afirmar que "O ato de narrativizar reatribui significado aos eventos em termos de suas consequências, isto é, de como a história se desenvolve e termina, e não em termos do seu lugar temporal na sequência de eventos". O tempo narrativo, portanto, é central para a maneira como uma história é estruturada e entendida, e o ordenamento temporal é simplesmente uma estratégia para organizar os eventos em um enredo.

Nessa perspectiva, o tempo na narrativa aqui é considerado segundo o modelo descritivo experiencial, privilegiando a concepção relacional, de pluralidade de subidentidades de que fala Mishler (2002). Segundo esse autor, os modelos descritivos da mudança progressiva baseados na ordem temporal tratam o desenvolvimento da identidade como um processo unitário, como se cada vida pudesse ser definida por um único fio de enredo. "Tal visão suprime nossas múltiplas identidades, que refletem nosso posicionamento em diferentes contextos relacionais, e ignora as sequências sobrepostas de eventos e sua intersecção umas com as outras." (Mishler, 2002, p.110)

Sacks (1984) também refere o fato de as pessoas não construírem narrativas de qualquer maneira, simplesmente contando os fatos. Sacks defende que as pessoas tendem a normalizar a experiência ao construir narrativas. Dessa forma, visam apresentar uma visão do mundo como uma pessoa normal faz. Sacks (1984) mostra com um exemplo o fato de que ser normal não é fácil para as pessoas, mas dá trabalho. Além disso, existem restrições, numa narrativa, ao que se pode e ao que não se pode contar para que se passe uma visão do mundo como uma pessoa normal faz. O exemplo do autor é:

\begin{abstract}
Se você, ao voltar para casa, relata com detalhes a aparência da grama ao longo da estrada; que havia quatro tonalidades diferentes de grama, algumas tendo aparecido no dia anterior devido à chuva, os ouvintes poderão estranhar e tentar interpretar o porquê desse relato. E se você agir assim rotineiramente, então as pessoas poderão pensar que há algo de estranho em você, que você é pretencioso. Você poderá pensar que eles estão com ciúmes de você. Você poderá perder amigos. (Sacks, 1984, p. 418)
\end{abstract}

Sacks (1984) explica que não se aceita alguém atribuindo mais emoção a um determinado evento do que o considerado normal. Por isso, há um monitoramento por parte das pessoas, quanto às experiências vividas e as características que fariam dessas experiências narrativas contáveis ou não, e isso interfere na vivência da própria experiência. As pessoas, então, armazenam experiências de modo que tenham o que contar quando tiverem uma oportunidade.

A construção da história de um indivíduo será diferente dependendo do momento em que este indivíduo a conta, ou, nos termos de Ricoeur (1980), dependendo de seu final, o qual tem função primordial no processo da construção da história ou do seu enredo. Autores como Kermode (1967) e Doctorow (2000) defendem a importância do término de uma história para que se possa entender como os eventos anteriores na sequência funcionam como começos e meios. Apenas através da determinação do final de uma história é que se podem determinar quais eventos pertencem à sequência e quais não pertencem.

Como mostra Mishler:

Lembramo-nos do nosso passado e continuamente o re-historiamos, variando a significância relativa de diferentes eventos de acordo com a pessoa em quem nos transformamos, descobrindo conexões das quais não estávamos previamente cientes, reposicionando-nos a nós mesmos a aos outros em nossas redes de relações. (Mishler, 2002, p.105).

Considerando as narrativas de pessoas com experiência de adoção, o final da história determinará as relações que seus eus parciais travaram e travam com os outros e com a experiência de terem sido adotados. A coerência e outras propriedades obrigatórias em suas narrativas será relativa, conforme Mishler (2002), uma vez que estão continuamente re-historiando seu passado e, consequentemente, os eventos relacionados à sua adoção, reposicionando-se a si mesmos a aos outros em suas redes de relações.

\title{
Adoção e construção da identidade: o papel da narrativa
}

Para Bruner (1990), é através da narrativa que se torna compreensível para si mesmo o que acontece de excepcional nas vidas cotidianas de cada um, organizando a experiência e a memória de acontecimentos humanos. 
A experiência de ter sido colocado para adoção é marcante na vida de qualquer pessoa que a vivencia, e, se isso ocorre na fase da pré-adolescência, coincidirá com o período da vida em que surge a necessidade de construção de uma identidade que permita à pessoa uma relação produtiva com o mundo. Durante esta fase, os indivíduos reúnem condições sociocognitivas para a construção de narrativas autobiográficas coerentes (Vieira \& Henriques, 2013). Segundo os autores, a formação de uma identidade narrativa envolve a construção de histórias coerentes, com a finalidade de criar e comunicar um sentido de identidade e de significado.

Considerando que os jovens que foram adotados defrontam-se com o desafio de desenvolver um sentido de self como pessoas adotadas (Von Korff, 2008), durante a adolescência eles começam a refletir a respeito disso e a integrar suas reflexões e experiências em uma identidade narrativa significativa e coerente. Segundo Grotevant (1997), a identidade narrativa de ser adotado é construída quando os jovens começam a refletir sobre o significado de terem crescido cuidados por famílias adotivas, enquanto permanecem geneticamente relacionados às famílias biológicas. Ela surge no momento em que esses jovens conseguem lidar com essas questões, organizando lealdades em relação a suas famílias e respondendo às demandas sociais, através da percepção dos outros, em relação a terem sido adotados (Vieira \& Henriques, 2013).

A interioridade, assim como a experiência do sujeito com o mundo, é organizada narrativamente, por isso considera-se que a identidade resulta de um processo sociocultural de construção de significado. Ao invés de ter existência apenas na cabeça de cada indivíduo, a identidade é construída interpessoalmente (Fivush, 2008; Fivush \& Baker-Ward, 2005; Fivush \& Buckner, 1998; Fivush \& Haden, 2003).

Como cada cultura representa o significado de pessoalidade de maneira peculiar, cada indivíduo negocia tais significados com a cultura em que se insere ao definir a sua identidade através de significados pessoais e coletivos, cada um com o peso que lhe atribui a própria cultura (Fivush, 2008; Fivush \& Baker-Ward, 2005; Fivush \& Buckner, 1998; Fivush \& Haden, 2003). O kit de ferramentas referido por Bruner (1987) diz respeito exatamente às ferramentas utilizadas nessa negociação, um processo em que o indivíduo, assumindo papel de protagonista, elabora narrativas sobre si mesmo. Esse processo de autoconstrução é, segundo Bruner (1987), um organizador da identidade e pode partir de narrativas conhecidas culturalmente, como romances, comédias, entre outras.

Como nos mostra Fivush (2008), as habilidades cognitivas construídas na infância de um indivíduo encontram-se em pleno desenvolvimento durante a adolescência. Essas habilidades são responsáveis pela elaboração de narrativas autobiográficas coerentes, além de capacitar o adolescente a se posicionar em sociedade, satisfazendo exigências socioculturais, segundo Habermas (2007) e Habermas e Bluck (2000). Disso McAdams e McLean (2013) nos levam a concluir que a história de vida é o meio pelo qual se organiza a identidade, pois, para construir uma história de vida, a construção da identidade psicossocial do indivíduo deve estar bem encaminhada.

As histórias de vida são construídas pelos adolescentes em conjunto com as pessoas ao seu redor e com seu contexto sociocultural. Segundo McLean, Pasupathi e Pals (2007), eles tentam encontrar unidade e objetivos na vida e no mundo através da construção de narrativas autobiográficas, paralelamente à sua tentativa de encontrar sentido no presente e planejar o futuro. Por meio de suas autobiografias, os adolescentes organizam sentimentos, pensamentos, funções sociais e relacionamentos, integrando, assim, os fatos no self sincronicamente. Os adolescentes, então, através de narrativas autobiográficas, configuram a sua identidade. São capazes de admitir que antes pensavam e agiam de forma diferente do que no presente, o que os capacita a integrar seu self entre os adultos. Além disso, organizam suas crenças e posicionamentos diante da vida no momento presente.

A identidade narrativa dos indivíduos adotados é marcada pelo constante movimento de busca por suas origens, por seus pais biológicos e por um sentido de vida que foi perdido, que faria a conexão entre passado, presente e futuro. Em outras palavras, segundo Carsten (2000) e Yngvesson (2007), por terem tido suas famílias originais interrompidas, jovens adultos adotados enfrentam sentimentos de ruptura com o passado. Tanto segundo a legislação internacional, quanto segundo as leis para adoção em países individualmente considerados, o indivíduo que é adotado é integrado em uma família adotiva que deve cortar seus laços com a família biológica, produzindo, assim, uma família "as-if", como se fosse biogenética. Isso, Yngvesson (2007) ressalta, é uma questão cultural que reforça ainda mais a ruptura enfrentada pelos indivíduos adotados.

Considerando, conforme dito acima, que a identidade narrativa de jovens adultos adotados é marcada pelo sentimento de uma ruptura com o passado, o que os leva a buscar sua origem ao procurar seus pais biológicos, procurando recuperar um sentido perdido de continuidade entre o passado, o 
presente e o futuro, a re-historiação, segundo Mishler (2002), está predominantemente atrelada aos fatos relacionados à adoção, no caso das narrativas de adotados.

Neste estudo, intenta-se demonstrar como a adoção aparece nas narrativas de vida de indivíduos com essa experiência, à medida que re-historiam o seu "eu" nessa narrativa, a partir de seu final, conforme concepção de Mishler (2002), Riccoeur (1980), Kermode (1967) e Doctorow (2000), sendo o final determinado por quem constrói a história, não por algum ou mais eventos relatados cronologicamente, o que se limitaria a uma visão linear de narrativa.

\section{Método}

Foi utilizado um banco de dados construído para a pesquisa de Vieira (2012) ${ }^{1}$, composto por narrativas de jovens adultos com experiência de adoção. Selecionaram-se duas narrativas, a de Beno e a de Beatriz, como são chamados de maneira fictícia. Ambos tinham 22 anos na época em que produziram suas narrativas e ambos tinham sido adotados durante a pré-adolescência. A diferença entre eles é que a narrativa de Beatriz havia sido classificada como coerente e a de Beno, como incoerente, na pesquisa de Vieira (2012). Ambas foram transcritas e analisadas, considerando-se o conteúdo narrado à luz das teorias da identidade e da narrativa aqui descritas, além de características rítmicas e outras propriedades da fala em interação, conforme praticadas pela Análise da Conversa Etnometodológica² .

Destacou-se a presença dos eventos relacionados à adoção na re-historiação dos pesquisados e na constituição de seus “eus” parciais, conforme Mishler (2002), mostrando-se também a relação entre as características rítmicas próprias da fala e outras propriedades como hesitações e repetições com o que está sendo dito. Considera-se, de acordo com Ricoeur (1980), que a narrativa é construída a partir do seu final. "Por isso, o final da história tem uma função primordial no processo de construção da história ou do seu enredo" (Mishler, 2002, p.101). Kermode (1967) e Doctorow (2000) foram os inspiradores de tais concepções de Ricoeur:

Conforme apontam Kermode e Doctorow, temos de saber como uma história termina para só então podermos entender como os eventos anteriores na sequência funcionam como começos e meios. Além disso, antes dessa avaliação, não podemos determinar quais eventos pertencem à sequência e quais não pertencem sem antes termos definido o final. (Mishler, 2002, p. 103)

Como apontado por Vieira (2012), a narrativa de Beno não alcançou índices satisfatórios de coerência, o que, segundo McAdams (2001), reflete o caráter conflituoso, contraditório e ambíguo da identidade de Beno. Por outro lado, na narrativa de Beatriz observa-se que a experiência da adoção encontra-se integrada e os afetos, embora intensos, estão organizados em uma construção de sentido que transforma sua história de vida em aprendizagem.

\section{Apresentação e análise dos resultados}

Beatriz, por ter seus pensamentos organizados e alcançado unidade entre os fatos de sua existência, consegue construir uma narrativa coerente e demonstra capacidade de normalizar os eventos que conta, segundo noção de Sacks (1984). Isso pode ser observado nos excertos 1 e 2:

\section{Excerto 1 - transcrição de fala da narrativa de Beatriz}

Tudo o que vem de trás né: são coisas que: nunca vou esquecer como é óbvio, mas são coisas que ficam para sempre (.) e: por muito mais que eu sei que tenho a situação resolvida (.) sempre que conto sou capaz de chorar ou sou capaz de pronto me lembrar dessas coisas, mas hã lembro perfeitamente de meus pais....

\footnotetext{
${ }^{1}$ Essas narrativas fazem parte do corpus da pesquisa de Vieira (2012), realizada na cidade de Porto, em Portugal. Como o país não possui legislação que obrigue a existência de avaliação em comitês de ética, não se apresenta, neste estudo, parecer desse gênero. Em Vieira (2012), as narrativas de vida foram submetidas a uma análise descritiva de estrutura, processo e conteúdo, baseada nos sistemas de Gonçalves, Henriques et al. (2002; 2006a; 2006b; 2006c). As narrativas foram também analisadas segundo o modelo tridimensional de coerência global de narrativas de vida de Habermas e Diel (2005), Habermas e Silveira (2008) e Habermas, Ehlert-Lerche e Silveira (2009). Foi também observada a relação dialógica entre as posições do eu e dos outros tal como o proposto por Fivush (2008). Foram consideradas, na análise da identidade narrativa, as relações do eu narrador com os modelos culturais, tanto por identificação como por oposição (Fivush, 2008; Adler e McAdams, 2007; Habermas, 2007). A multiplicidade de caracteres, imagos e vozes do discurso narrativo foi analisada descritivamente segundo os constructos de McAdams (1993), Hermans e Kampen (1993) e Hermans (2008).

2 As transcrições apresentadas neste trabalho foram feitas segundo as convenções de Jefferson (1984) que se encontram em anexo, no Quadro 1, em anexo. 


\section{Excerto 2 - transcrição de fala da narrativa de Beatriz}

quando eu dizia e falava-se na escola ai o teu pai o teu pai (.) eu sentia necessidade de dizer (.) olha (.) eu não tenho pai (.) pronto. >mas as pessoas passavam a: criar coisas ai morreu não morreu teve um acidente. $<$ coisas completamente ridículas. que eu se calhar sentia bem melhor. não é se calhar. é mesmo. eu sentia melhor dizer é isso (.) eu sou adotada e: minha mãe é sozi:nha não tinha problema absolutamente nenhum (.) nunca senti discriminação nenhuma (.) nenhuma mesmo. claro que as pessoas perguntavam ai o que aconteceu (.) mas eu não me importava nada em contar. é o que eu digo (.) tipo: é algo que me vai me acompanhar para o resto de minha vida. não é por que: nada não é nada que: uma coisa que: nada vai apagar não é: a memória não apaga isto e: eu sei o que vivi e sei o que passei (.) e se calhar sou uma pessoa difere:nte por aquilo que passei. eu sou mais não sou mais que ninguém não me considero mais que ninguém. mas claro que - ao lado de amigas minhas não é (.) > se calhar tenho outras< - não é se calhar (.) tenho outra história de vi:da (.) e sei que sou outra pessoa por essa história de vida (.) >não estou a dizer que sou uma pessoa melhor ou pior <. (.) pronto. mas tenho a minha história e tenho: a minha = as minhas coisas (.) e são coisas que vão me acompanhar para sempre né (.) pronto. portanto. de amigos nunca senti assim discriminação nenhuma $=$ nenhuma mesmo (.) hã: as pessoas claro perguntaram sempre o que é que se o que é que se tinha passado (.) como é que foi como é que não fo:i hã aquelas perguntas de praxe mesmo. eu dizia. (não sei não há mal ou nunca xxxx). hã:: nem nunca: soube (.) de ninguém que falasse mal (1.0) nunca senti nada: em relação: hã à adoção. nunca senti (.) nunca senti (.) em nenhum aspecto de minha vida que: sou adotada (.) não: não sinto pronto (.) não é uma coisa que:: (1.0) que eu sinta (.) não sinto nada disso. nunca senti.

Fonte: transcrição das falas gravadas em Vieira (2012)- 16.09

Quanto às repetições e outras propriedades rítmicas da fala de Beatriz, pode-se tirar algumas conclusões. Não há intensa alteração na entoação, nem no volume de voz, nem nos alongamentos de vogais, nem tampouco nas pausas. Na primeira fala transcrita acima (excerto 1), a pesquisada revela claramente que o tema da adoção é um tópico já muito historiado e re-historiado, e que este final, que, na verdade, é o início de sua narrativa, conforme a noção de Mishler (2002), marca mais uma re-historiação, em que ela novamente se posiciona perante os fatos relacionados à experiência de adoção, desta vez com mais abstração do que das outras vezes, mas, mesmo assim, revelando intensa carga de afeto. Já no excerto 2, as repetições são muitas, principalmente no que se refere ao fato de não ter se sentido discriminada. Ela demonstra estar fazendo o esforço social (Sacks, 1984) necessário para parecer uma pessoa normal, para se recuperar do preconceito que ela mesma talvez atribua a si própria, dando a entender que esperava sofrer discriminação, o que não acontece.

No excerto 1, Beatriz diz que tudo o que aconteceu jamais será esquecido por ela e que, por vezes, ela chora em função disso. Pode-se dizer que o final da história, desta história de vida contada por Beatriz, marca uma re-historiação dos eventos relacionados à sua adoção no sentido de acomodá-los entre os demais eventos de sua vida. Ela integra a experiência de adoção entre os fatos de sua vida, de maneira que ter sido adotada passa a ser muito natural, embora ela admita que isso sempre lhe causará dor e mágoa.

Isso também fica evidente no excerto 2 , em que a pesquisada demonstra normalização de suas experiências e, com ênfase e naturalidade, afirma nunca ter sido discriminada por amigos quanto à sua situação de adotada. Observa-se, na transcrição de sua fala, que ela se refere a esse assunto com objetividade, sem hesitações, com pausas definidas e sem alteração na tonalidade e volume da voz.

A narrativa de Beatriz demonstra o que propõem Baerger e McAdams (1999) e Adler, LodiSmith, Philippe e Houle (2016): uma narrativa autobiográfica coerente está relacionada tanto ao bemestar como a uma abertura a novas experiências e à capacidade pessoal para desenvolver-se. A carga de afeto atribuída ao fato de ter sido adotada é estruturadora, uma vez que Beatriz está abertamente procurando melhores condições de vida, experiências realizadoras e bem estar.

Ao contrário da narrativa de Beatriz, Beno narra sua história de forma circular, demonstrando não ter conseguido ainda construir um sentido para sua experiência de adoção. Dessa forma, a sua narrativa é entrecortada por conjeturas a respeito do porquê de ter sido abandonado por seus pais biológicos e colocado para adoção, conforme excertos 3 e 4 :

\section{Excerto 3 - transcrição de fala da narrativa de Beno}

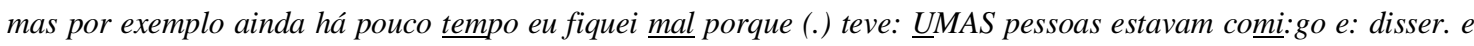
eu tava a brincar a dizer que: (1.0) que era adotado lá de ator co(hhh)nhecido (.) e que e::: mmm e::: >depois eles perguntaram se eu era adotado< daí eu comecei a falar da minha históriä: de vida e:: (.) isso aí trouxe-me assim 
marcas que eu não queria tocar nestas feridas (.) mas tive que tocar e passei u:m tempo mal. (.) a pensar nestas coisas só queria sair daqui e:: e pronto. (.) estragar a minha vida.

Fonte: transcrição das falas gravadas em Vieira (2012)- 11.33

\section{Excerto 4 - transcrição de fala da narrativa de Beno}

eu agora falo abertamente disto só que:: às vezes inda:: > pronto às vezes custa um bocado tocar nessa ferida< e:: e quando::: e lá na escola $:$ como a escola é:: é muito pequena e lá sabe-se tudo, e:: não sei contar $i::$ sso (.) pra muitas pessoas pode:: (2.0) quer dizer > pelo menos para mim, podem me magoar.$<$ e podem me ver de maneira diferente e:: e eu não quero isso:: > quero ser uma pessoa normal $<$ não é? já passei pelas minhas dificuldades mas (.) não quero ser mai::s acarinhado (.) do que os outros só porque sou adotado e porque:: porque > agora estou numa família nova é isso $\leq \mathbf{1}(2.0)^{\circ}$ quero ser normal ${ }^{\circ}$ (2.0) aconteceu mas já foi e agora:: hoje tenho minha nova vida que:: $(x \times x \times x x)(1.0)>$ espero que seja assim até o fim.<

Fonte: transcrição das falas gravadas em Vieira (2012) - 27.37

Observa-se, na fala de Beno, que o tema da adoção causa alteração de volume e tonalidade na voz, alongamentos e alteração na velocidade com que fala, além de várias pausas e repetições, como se o assunto alterasse bastante seu estado emocional, causando alterações na forma como se expressa. Claramente, Beno ainda demonstra uma carga muito grande de afeto em relação ao fato de não ter sido criado pelos pais biológicos, mas, diferentemente de Beatriz, essa carga é desestruturadora. Beatriz demonstra afeto estruturado em relação ao tema.

Poder-se-ia atribuir a Beno uma certa incompetência pragmática, por expressar abertamente sua insegurança em relação à sua adoção, não conseguindo parecer normal. Ele não consegue reconhecer a falta de normalidade do fato de ter sido adotado, mas, mesmo assim, tratar do tema num nível abstrato, distanciando-o da realidade de seu dia a dia, procurando qualidade de vida, bem-estar e novas experiências. Isso é o que Beatriz faz. Beno, por sua vez, chega a procurar novas experiências, como o teatro e a faculdade, mas ele ainda se sente imobilizado quando o assunto "adotado" vem à tona.

O fato de ter sido adotado é algo muito difícil de aceitar, e Beno atribui emoções demasiadamente intensas quando se refere a isso, como mostra o excerto 3, no qual ele relata sua reação quando as pessoas no curso de teatro vêm a saber sobre sua adoção e comentam. Para ele, isso foi motivo de querer desistir da faculdade, quando, para seus colegas, provavelmente era apenas um fato novo, sem o poder de colocar Beno em qualquer outra categoria que não fosse a de colega. No momento em que Beno conta a sua história, isto é, a partir do final em que se encontra essa história e que ele decide ser seu final, Beno demonstra estar tão envolvido com o assunto da adoção que não consegue se desvencilhar dele e aumenta sua importância em situações nas quais ele ter sido adotado não tem relevância nenhuma na atividade que está sendo realizada.

Isso aparece também no excerto 4, quando, novamente, ele fala da escola (faculdade), dizendo que simplesmente contar sobre a adoção já o coloca numa posição muito delicada frente aos colegas, o que pode magoá-lo e, mais adiante, afirma querer ser uma pessoa normal. Sua re-historiação dos fatos passados não o capacita a contá-los como uma pessoa normal faz, chegando a deixar implícito que uma pessoa adotada não é normal.

\section{Considerações finais}

Conforme demonstram as análises e conclusões acima, é possível identificar o processo de rehistoriação em narrativas de vida, no caso aqui estudado em narrativas de vida de adotados. Neste estudo foi possível constatar a função do final da história de determinar a maneira como a narrativa é construída, como os eventos são organizados, adquirem significações e como os eventos anteriores na sequência funcionam como começos e meios. Como apontam Kermode (1967) e Doctorow (2000), não podemos determinar quais eventos pertencem à sequência e quais não pertencem sem antes termos definido o final.

Esta pesquisa estudou dois casos distintos, nos quais a história termina de maneira distinta, o que levou cada narrador a atribuir significado à adoção de maneira bem diferente um do outro e também a posicionar-se diferentemente em relação a essa experiência. Enquanto Beatriz partiu de um final em que procura seu bem estar, novas experiências e desenvolvimento pessoal, Beno parte de um final em que ainda se encontra numa situação de negatividade predominante quanto ao seu passado e o fato de ter sido colocado para adoção. Dessa forma, Beatriz tem uma visão positiva quanto ao seu status de adotada, não identificando nenhuma situação de discriminação em sua vida em função dessa condição, ao passo que Beno ainda tem dificuldade até para ser identificado como adotado, considerando tal condição um 
desabono pessoal e, consequentemente, causador de preconceito por parte da sociedade em que vive e das pessoas com quem se relaciona.

As contribuições desta pesquisa estendem-se por diferentes áreas. Por um lado, ela contribui para a psicologia, ao investigar a formação da identidade através da análise de narrativas produzidas por indivíduos pesquisados. Por outro, também presta contribuição para a promoção da saúde, na esfera mental, ao abordar um grupo vulnerável, os adotados. Também para o desenvolvimento humano, uma vez que a qualidade de vida de grupos vulneráveis passa pelo desenvolvimento de sua capacidade para re-historiar seu passado e para atingir o poder de contar uma história de vida em que haja unidade de significado, na qual os indivíduos veem-se como pessoas capazes de integrar suas experiências dolorosas em uma vida próspera e feliz.

\section{Referências}

Adler, J. M., \& McAdams, D. P. (2007). Time, culture, and stories of the self. Psychological Inquiry, 18(2), 97-128.

Adler, J. M., Lodi-Smith, J., Philippe, F. L., \& Houle, I. (2016). The incremental validity of narrative identity in predicting well-being: A review of the field and recommendations for the future. Personality and Social Psychology Review, 20(2), 142-175.

Baerger, D. R., \& Mcadams, D. P. (1999). Life story coherence and its relation to psychological wellbeing. Narrative Inquiry, 9, 69-96.

Bamberg, M., \& Georgakopoulou, A. (2008). Small stories as a new perspective In narrative and identity analysis. Text \& Talk, 28(3), 377-396.

Bastos, L.C., \& Biar, L.A. (2015). Análise de narrativa e práticas de entendimento da vida social. D.E.L.T.A., (31-especial), 97-126.

Bruner, J. (1987). Life as narrative. Social research, 54(1), 11-32.

Bruner, J. (1990). Acts of meaning. Cambridge: Harvard University Press.

Carsten, J. (2000). Knowing where you've come from: rupture and continuities of time and kinship in narratives of adoption reunions. Journal of Royal Anthropological Institute, 6, 687703.

Correia, M. F. B. (2003). A constituição social da mente: (re)descobrindo Jerome Bruner e construção de significados. Estudos de Psicologia, 8(3), 505-513.

Doctorow, E.L. (2000). City of God. Nova York: Random House.

Erikson, E. H. (1968). Youth and identity. New York: Norton.

Fivush, R. (2008). Remembering and reminiscing: How individual lives are constructed in family narratives. Memory Studies, 1(1), 49-58.

Fivush, R., \& Buckner, J. P. (1998). Gender and self in children's autobiographical narratives. Applied Cognitive Psychology, 12, 407-429.

Fivush, R., \& Haden, C. A. (2003). Autobiographical memory and the construction of a narrative self: Developmental and cultural perspectives. Mahwah, NJ: Lawrence Erlbaum Associates.

Fivush, R., \& Baker-Ward, L. (2005). The search for meaning: Developmental perspectives on internal state language in autobiographical memory. Journal of Cognition and Development, 6(4), 455-462.

Freeman, M. (2006). Life “on holiday”? In defense of big stories. Narrative Inquiry.

16(1), 131-138.

Gonçalves, O. F., Henriques, M. R., Alves, A., \& Soares, L. (2002). Analyzing structure, process and content in narratives of patients diagnosed with agoraphobia. Revista Internacional de Psicologia Clínica y de la Salud, 2(3), 389-406.

Gonçalves, O. F., Henriques, M. R., \& Cardoso, G. (2006 ${ }^{a}$. Sistema de avaliação da matriz narrativa: Coerência estrutural narrativa. Braga: Departamento de Psicologia da Universidade do Minho.

Gonçalves, O. F., Henriques, M. R., Alves, A., \& Rocha, C. (2006b). Sistema de avaliação da matriz narrativa: Complexidade do processo narrativo. Braga: Departamento de Psicologia da Universidade do Minho.

Gonçalves, O. F., Henriques, M. R., Soares, L., \& Monteiro, A. (2006c). Sistema de avaliação da matriz narrativa: Diversidade de conteúdo narrativo. Braga: Departamento de Psicologia da Universidade do Minho.

Grotevant, H. D. (1997). Coming to terms with adoption: The construction of identity from adolescence into adulthood. Adoption Quarterly, (1), 3-27.

Habermas, T. (2007). How to tell a life: The development of the cultural concept of biography. Journal of Cognition and Development, 8(1), 1-31. 
Habermas, T., \& Bluck, S. (2000). Getting a life: The emergence of the life story in adolescence. Psychological Bulletin, 126(5), 748-769.

Habermas, T., \& Diehl, V. (2005). Three dimensions of global coherence: Global Rating scales. Frankfurt: Goethe University.

Habermas, T., \& Silveira, C. (2008). The development of global coherence in life narratives across adolescence: temporal, causal and thematic aspects. Developmental Psychology, 44, 707-721.

Habermas, T., Ehlert-Lerche, S., \& Silveira, C. (2009). The developmentof the Temporal macroestructure of life narratives across adolescence: Beginnings, linear narrative form, and endings. Journal of Personality, 77(2), 527-559.

Hermans, H. J. M. (2008). How to perform research on the basis of dialogical self theory? Introduction to special issue. Journal of Constructivist Psychology, 21, 185-199.

Hermans, H. J. M., \& Kempen, H. J. G. (1993). Imaginal dialogues in the self: theory and method. Journal of Personality, 61(2), 207-236.

Jefferson, G. (1984). Transcript notation. In J. M. Atkinson; J. Heritage. (eds.). Structures of social action: studies in conversation analysis. (pp.9-26). Cambridge: University Press.

Kermode, F. (1967). The sense of an ending: studies in the theory of fiction. Nova York: Oxford University Press.

Labov, W., \& Waletzky J. (1967). Narrative Analysis: oral versions of personal experience. In J. Helm. (ed.) Essays on the verbal and visual arts. (pp.12-44). Seattle: University of Washington Press.

Labov, W. (1972). Language in the inner city: studies in the Black English Vernacular. Philadelphia: University of Pennsylvania Press.

Linde, C. (1993). Life Stories: the creation of coherence. New York: Oxford University Press.

McAdams, D. P. (1993). The stories we live by: Personal myths and the making of the self. New York: The Guilford Press.

McAdams, D. P. (2001). The psychology of life stories. Review of General Psychology, 5(2), 100-122.

McAdams, D. P., \& Mclean, K. C. (2013). Narrative identity. Current Directions in Psychological Science, 22(3), 233-238.

Mclean, K. C., Pasupathi, M., \& Pals, J. L. (2007). Selves creating stories creating selves: A process model of self-development. Personality and Social Review, 11, 262-278.

Mishler, E.G. (1986). Research interviewing. Context and narrative. Cambridge: Harvard University Press.

Mishler, E.G. (1999).Storylines. Craftartists' narratives of identity. Cambridge: Harvard Univeristy Press.

Mishler, E.G. (2002). Narrativa e identidade: a mão dupla do tempo. In: L.P. Da L.P. Moita Lopes, L. P.; L. Cabral Bastos. (eds.) Identidades: recortes multi e interdisciplinares. (pp..97-122). Campinas: Mercado de Letras.

Reese, E., Yan, C., Jack, F., \& Hayne, H. (2010). Emerging identities: Narrative and self from early childhood to early adolescence. In: K. C. Mclean; M. Pasupathi (eds.), Narrative development in adolescence. (pp. 23-43). LLC: Springer Science.

Riccoeur, P. (1980). Narrative time. Critical Inquiry, 7(1), 169-190.

Sacks, H. (1984). On doing "being ordinary". In: J. M. Atkinson; J. Heritage. (eds.) Structures of social action: studies in conversation analysis. (pp. 413-440). Cambridge: Cambridge University Press.

Vieira, A.G. (2012). Construção Narrativa da Identidade em Jovens Adotados. Porto, Portugal. Tese de Pós-Doutorado, Universidade do Porto.

Vieira, A.G., \& Henriques, M.R. (2013). A Construção Narrativa da Identidade em Jovens Adotados: o Caso Beno. Análise Psicológica, 31(2), 145-157.

Vieira, A.G., \& Henriques, M.R. (2014). A Construção Narrativa da Identidade. Psicologia Reflexão e Crítica, 27(1), 163-170.

Von Korff, L. A. (2008). Pathways to narrative adoptive identity formation in Adolescence and emerging adulthood. Minnesota, EUA. Tese de doutorado, University of Minnesota.

Yngvesson, B. (2007). Parentesco reconfigurado no espaço da adoção. Cadernos Pagu, 29, 111-138. 
Quadro 1: Convenções de Transcrição CONVENÇÕES DE TRANSCRIÇÃO

\begin{tabular}{|c|c|c|}
\hline [texto] & Colchete & Indica sobreposição de vozes. \\
\hline$=$ & Fala colada & $\begin{array}{l}\text { Indica que não há espaço entre a fala de } \\
\text { um interlocutor e a fala do interlocutor } \\
\text { seguinte. }\end{array}$ \\
\hline$(1.8)$ & Pausa & $\begin{array}{l}\text { Medida em segundos ou décimos de } \\
\text { segundos. Representa a ausência de fala } \\
\text { ou vocalização. }\end{array}$ \\
\hline (.) & Micropausa & $\begin{array}{l}\text { Equivale a menos de } 0.2 \text { segundos de } \\
\text { ausência de fala ou vocalização. }\end{array}$ \\
\hline , & Vírgula & Entonação contínua. \\
\hline & Ponto final & Indica entonação descendente e final. \\
\hline ? & Ponto de interrogação & Indica entonação ascendente. \\
\hline- & Hífen & $\begin{array}{l}\text { Indica interrupção abrupta da fala em } \\
\text { curso. }\end{array}$ \\
\hline : & Dois pontos & Alongamento de vogal ou consoante. \\
\hline$>$ texto $<$ & Sinais de menor & $\begin{array}{l}\text { Indicam fala mais rápida em relação à } \\
\text { fala }\end{array}$ \\
\hline$<$ texto $>$ & Sinais de maior & $\begin{array}{l}\text { anterior e posterior. } \\
\text { Indicam fala mais lenta em relação à fala } \\
\text { anterior e posterior. }\end{array}$ \\
\hline${ }^{\circ}$ texto $^{\circ}$ & Grau & $\begin{array}{l}\text { Indica fala mais baixa em relação a } \\
\text { anterior e posterior. }\end{array}$ \\
\hline TEXTO & Maiúsculas & $\begin{array}{l}\text { Volume mais alto em relação ao contexto } \\
\text { anterior e posterior. }\end{array}$ \\
\hline Texto & Sublinhado & Indica sílaba, palavra ou som acentuado. \\
\hline 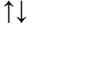 & Setas & $\begin{array}{l}\text { Indicam aumento ou diminuição na } \\
\text { entonação. }\end{array}$ \\
\hline $\begin{array}{l}\text { Hhh } \\
\text { (texto) }\end{array}$ & Parênteses & $\begin{array}{l}\text { Indicam expiração audível. } \\
\text { Indica dúvidas do/a transcritor/a. }\end{array}$ \\
\hline $\mathrm{xxxx}$ & & $\begin{array}{l}\text { Cada x indica uma sílaba que não foi } \\
\text { possível de se transcrever. }\end{array}$ \\
\hline$(($ texto $))$ & Parênteses Duplos & Comentários do/a transcritor/a \\
\hline (hhh) & Riso & Indica pulsos de riso. \\
\hline
\end{tabular}

Fonte: Jefferson (1984)

Recebido em: agosto de 2020

Aceito em: outubro de 2020

Margarida Rangel Henriques - Doutora em Psicologia pela Universidade do Minho - Portugal.

Docente da Faculdade de Psicologia e Ciências da Educação da Universidade do Porto.

André Guirland Vieira - Faculdade de Psicologia e Ciências de Educação da Universidade do Porto - Portugual. Docente no Programa de Pós-Graduação em Promoção da Saúde - Universidade Luterana do Brasil.

Dóris Cristina Gedrat - Doutora em Linguística Aplicada pela Pontifícia Universidade Católica do Rio Grande do Sul - Docente no Programa de Pós-Graduação em Promoção da Saúde - Universidade Luterana do Brasil.

E-mail para contato: doris.gedrat@ulbra.br. 